\title{
Schriftarten, Siglen und Zeichen
}

\begin{tabular}{|c|c|}
\hline ecte & Brieftext \\
\hline petit & Text von fremder Hand \\
\hline KAPITÄLCHEN & Briefkopf des Editors \\
\hline Sperrung & Hervorhebung im Brieftext \\
\hline S perrung & doppelte Hervorhebung im Brieftext \\
\hline perrung & dreifache Hervorhebung im Brieftext \\
\hline otesk & lateinische Schrift im Brieftext \\
\hline perrung & Hervorhebung in lateinischer Schrift im Brieftext \\
\hline kursiv & Editortext \\
\hline G? & zweifelhafte Eigenhändigkeit (bei Korrekturen) \\
\hline$x \times \times$ & $\begin{array}{l}\text { unlesbare Buchstaben im edierten Text und in den Va- } \\
\text { rianten }\end{array}$ \\
\hline abcd & unsichere Lesung im edierten Text und in den Varianten \\
\hline bcd $\rangle$ & Zusätze des Editors im edierten Text \\
\hline$\langle\quad\rangle$ & Textverlust der Vorlage im edierten Text \\
\hline & Abbrechungszeichen im edierten Text \\
\hline$\lceil\mathrm{abcd}\rceil$ & über der Zeile ergänzt \\
\hline$\lfloor$ abcd $\rfloor$ & unter der Zeile ergänzt \\
\hline$|\mathrm{abcd}|$ & in der Zeile ergänzt \\
\hline$\lceil\mathrm{abcd} \Gamma$ & am rechten Rand oder in der rechten Spalte ergänzt \\
\hline$\rceil \mathrm{abcd}\rceil$ & am linken Rand oder in der linken Spalte ergänzt \\
\hline$\downarrow$ abcd $\downarrow$ & am unteren Rand ergänzt \\
\hline & nachträgliche Trennung \\
\hline ר & nachträgliche Zusammenschreibung \\
\hline ed & gestrichen \\
\hline bed & Streichung in der Streichung \\
\hline abcd efgh & $\begin{array}{l}\text { Streichung vor der Niederschrift des folgenden Wortes oder } \\
\text { Zeichens (Sofortkorrektur) }\end{array}$ \\
\hline abcd efght ijkl & später ersatzlos gestrichen (Tilgung) \\
\hline cd efgh ijkl & durch Unterpungierung getilgte Streichung \\
\hline abcd efgh & $\begin{array}{l}\text { Stützwort zur eindeutigen Zuordnung einer varianten } \\
\text { Textstelle }\end{array}$ \\
\hline & gestrichen \\
\hline & $a$ überschrieben durch $b$ oder korrigiert $z u b$ \\
\hline
\end{tabular}


Seitenwechsel in der Handschrift; Absatzzeichen in den Varianten

|:abcd:| historische Klammerzeichen im Brieftext 
